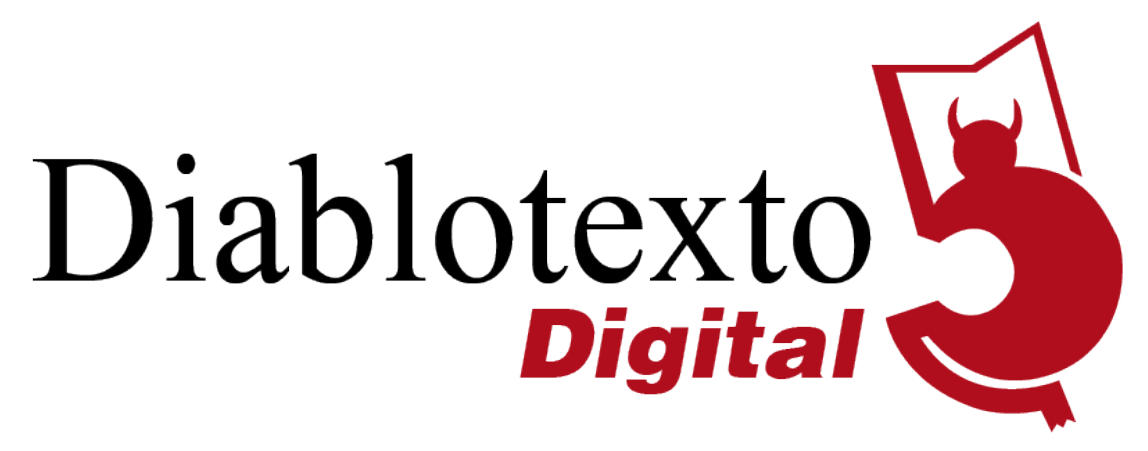

\title{
Salvadora Medina Onrubia y la Guerra Civil Española: la recepción de Un hombre y su vida en la Argentina de 1939
}

\author{
Salvadora Medina Onrubia and the Spanish Civil War: the reception of Un \\ hombre y su vida in Argentina, 1939
}

\author{
DANIELA SeRBER \\ UNIVERSIDAD DEL SALVADOR
}

Resumen: El 10 de marzo de 1939, se estrena en Buenos Aires Un hombre y su vida, de Salvadora Medina Onrubia (1894-1972), periodista y escritora argentina, militante anarquista y feminista. Tal como ella lo indica tras el título, la obra, escrita en 1936, nace "[b]ajo la advocación del momento encendido de España", la Guerra Civil, pero, significativamente, se lleva a escena cuando el desenlace era inminente.

En este trabajo, haremos un acercamiento a la recepción del estreno en la prensa argentina a través de las reseñas incluidas en periódicos de distintas ideologías.

Palabras clave: exilio republicano, Argentina, Salvadora Medina Onrubia, teatro

Abstract: On March 10, 1939, Un hombre y su vida, by Salvadora Medina Onrubia (1894-1972), an argentinian journalist and writer, an anarchist and feminist activist, was premiered in Buenos Aires. As she points out, the play, written in 1936, was born "under the advocation of the intense moment of Spain", the Civil War, but, significantly, it is staged when the outcome was imminent.

In this paper, we will focus on the reception of the première in the argentinian press through the reviews included in newspapers of different ideologies.

Key words: Republican exile, Argentina, Salvadora Medina Onrubia, theatre 


\section{Introducción}

El 10 de marzo de 1939, en el Teatro Maravillas de Buenos Aires, se estrenó Un hombre y su vida, de Salvadora Medina Onrubia (1894-1972), periodista y escritora argentina, militante anarquista y feminista. Tal como ella lo indica tras el título, la obra nació "[b]ajo la advocación del momento encendido de España" (Medina Onrubia, [1936] 2007: 147) ${ }^{1}$, la Guerra Civil Española, y fue publicada en septiembre de 1936. Pero se llevó a escena, significativamente, cuando el desenlace ya se vislumbraba y en el marco de eventos organizados en la ciudad en apoyo de los republicanos, muchos, exiliados en la Argentina.

Para algunos hombres y mujeres forzados a dejar su patria, la Argentina fue uno de los horizontes posibles del doloroso camino del destierro, pues, “¿[q]uién no tenía en estas tierras algún pariente? ¿Quién no conocía a alguien que testimoniara, a través de la recepción de remesas de dinero, cartas y fotografías, revistas y diarios, la gran generosidad de los argentinos?", plantea Emilia de Zuleta (1999: 35).

Como sabemos, el exilio republicano español fue masivo, de una amplia dispersión geográfica y excepcional en su duración por la longevidad de Francisco Franco y su dictadura (Lida, 1991: 67). Y, asimismo, como apunta José Luis Abellán (1989), "si abandonamos la esfera de la cantidad, y nos acercamos al ámbito de la cualidad, la magnitud del exilio se agiganta todavía más" (9). Esa importancia cualitativa "puede medirse con dos parámetros distintos: el de las grandes figuras y el de sus realizaciones", proyectos que "constituyen auténticos capítulos de la cultura española" (Abellán, 1989: 9).

A diferencia de lo que ocurrió en México debido a las políticas de recepción durante el gobierno de Lázaro Cárdenas (Lida, 1991: 67-72), en la Argentina, no hubo un apoyo oficial y explícito, lo cual determinó que los exiliados llegaran "a cuentagotas" y con un predominio de profesionales, académicos, artistas, científicos, periodistas y actores (Lida, 1991: 73). Sin

\footnotetext{
${ }^{1}$ La autora especifica la fecha de escritura al inicio de la obra: "Buenos Aires, julio 28 - agosto 17 de 1936". Todas las citas corresponden a esta edición.

Diablotexto Digital 8 (2020), 127-153 
embargo, en el plano internacional, la Argentina defendía de manera activa el derecho de asilo, lo cual le permitió construirse una imagen diplomática de "reserva moral" y, así, jugar un rol importante en los temas referidos a la ayuda humanitaria (Schwarzstein, 2001: 51-52).

A esta contradicción, se sumaba la división de la sociedad respecto al conflicto: no solo los argentinos estaban confrontados, sino los mismos españoles residentes en el país. No obstante, de manera simultánea, creció un movimiento de apoyo y solidaridad, primero, para con la República durante la contienda y, luego, para con los exiliados del franquismo. Aunque fue animado, en su mayor parte, por actores de peso en la sociedad, involucró a gran parte del pueblo, de manera que los exiliados que fueron llegando a la Argentina a partir de mediados de 1939 se encontraron con una sociedad movilizada por la causa (Schwarzstein, 2001: 102-138). Asimismo, descubrieron un entramado de asociaciones españolas que les permitía sentirse parte de una comunidad, "aunque fuera «imaginada», en términos de Anderson (1993)", y "mantener y recrear, al menos durante los primeros años, una identidad nacional" (Ortuño Martínez, 2016: 143-144; ver también Lida, 1991: 73). Un lugar destacado ocupó también el Centro Republicano Español de Buenos Aires, representante oficial, primero, de la España republicana y, luego, de la antifranquista en Argentina.

En este contexto, la situación de las elites profesionales, académicas, artísticas y científicas, como sabemos, fue diferente de la de la mayoría. La Argentina era un país de gran vitalidad cultural arraigada y propicia para el desarrollo científico y artístico, cuyo universalismo y cosmopolitismo profundizados durante el siglo $\mathrm{XX}$ por la coexistencia de desterrados de diversas regiones, en momentos diferentes y por diversos motivos - la convirtió en un escenario singularmente apropiado (Lida, 1991: 74; Zuleta, 1999: 11-12). Muchos exiliados de estos ámbitos consiguieron contratos de trabajo que les facilitaba tanto el ingreso en el país, como su permanencia, gracias a la actuación de distintos "mediadores" del mundo cultural e intelectual. En este sentido, es emblemático el episodio protagonizado por Natalio Botana, director 
del periódico Crítica y esposo de Medina Onrubia, ante la llegada del vapor Massilia el 5 de noviembre de 1939 (Schwarzstein, 2001: 123-138)².

De esa red de contención, formó parte el mundo teatral, en el que confluyeron grandes compañías argentinas y españolas asentadas ya en nuestro país o que llegaban de gira, como la Compañía Española de Comedias de Pedro López Lagar, que estrena Un hombre y su vida. En Buenos Aires, ello contribuyó a diseñar un sistema teatral que, "no siendo propiamente argentino, tampoco será percibido por la sociedad que lo sustenta como extranjero" y, así, la ciudad se convirtió en "la capital teatral de España en América" (Diago, 1994: 21). Esta situación de convivencia facilitó la inserción en el circuito de hombres y mujeres de teatro republicanos (directores, actores, escenógrafos, vestuaristas...) cuando estalló la Guerra Civil y debieron permanecer en el exilio. Es el caso de Helena Cortesina y Pedro López Lagar, protagonistas de la obra de Medina Onrubia (Ver Diago, 1994 y 2006).

Sin embargo, solo algunas pocas obras (y de distinto valor artístico) abordaron la cuestión de la Guerra Civil Española y una de ellas fue Un

\footnotetext{
${ }^{2}$ A bordo del vapor Massilia - que había partido de la ciudad francesa La Pallice el 18 de octubre y llegó al puerto de Buenos Aires tras haber eludido ataques de submarinos nazis-, se encontraban ciento cuarenta y siete españoles republicanos, quienes estaban en tránsito hacia Chile, Paraguay y Bolivia (Schwarzstein, 2001: 124). En ese grupo, se destacaban sesenta intelectuales, entre ellos, el pintor y escenógrafo Gregorio (Gori) Muñoz, la escritora Elena Fortún, el dramaturgo Pascual Guillén y el periodista Clemente Cimorra (Crítica, 5 de noviembre de 1939, p. 6). La persecución que habían sufrido, las lamentables condiciones en las que viajaron los pasajeros y la imposibilidad de descender dadas las restricciones de ingreso en la Argentina motivaron la difusión de la noticia y de las fotos de los retenidos saludando desde los ojos de buey del barco a la gran cantidad de gente que se había congregado en su apoyo: "A través de los medios que defendían la legalidad de la II República española y a sus partidarios se acusaba al Gobierno argentino de ignorar su tradicional política de asilo, así como de retener y negar la entrada a algunas de las principales figuras de la intelectualidad española que huían de la represión franquista. La presión que la opinión pública ejerció sobre el Gobierno argentino hizo que éste se viera obligado a permitir que los españoles y españolas en tránsito a otros países desembarcaran y permanecieran en Argentina" (Ortuño Martínez, 2012: párr. 7 y 8). En este contexto, se presentó en el puerto Natalio Botana, quien, a través de Crítica, había logrado recaudar fondos durante meses para ayudar a los intelectuales españoles refugiados en Francia y, asimismo, había solicitado al presidente Ortiz su entrada en la Argentina (Schwarzstein, 2001: 131). Botana pudo concretar el ingreso de los intelectuales, a quienes les ofreció dinero para facilitarles su asentamiento en el país y, a algunos de ellos, trabajo en su periódico; finalmente, Ortiz autorizó su permanencia (Schwarzstein, 2001: 125, 133). Este episodio se rodeó de un halo de leyenda y quedó grabado en la memoria de la colectividad española en la Argentina en general y en los exiliados en particular (Ortuño Martínez, 2012: párr. 8). Botana se había convertido en una figura "mítica": en el protector, en el salvador, de los republicanos españoles (Schwarzstein, 2001: 136-137).
}

Diablotexto Digital 8 (2020), 127-153

doi: $10.7203 /$ diablotexto.8.17685 
hombre y su vida, que recibió distintos tipos de críticas (Diago, 1995). Las publicaciones de la época proporcionan valiosa información sobre todo ello, por lo que haremos una aproximación a la recepción del estreno de la pieza a partir de las reseñas aparecidas en periódicos de distintas tendencias ideológicas y de los avisos promocionales incluidos en Crítica, lo cual nos permitirá, entre otras cosas, vislumbrar el valor de la mirada de Medina Onrubia acerca de un momento clave para España ${ }^{3}$.

\section{Una mujer y (algunos aspectos de) su vida}

La figura de Salvador Medina Onrubia, "la Venus roja”, fue adquiriendo una nueva dimensión en los últimos años a través de distintas obras y eventos que permitieron discutir las restrictivas etiquetas de "esposa de Natalio Botana" y de "abuela de Copi" . Maestra en la provincia argentina de Entre Ríos, madre soltera, periodista, traductora, escritora, seguidora de la teosofía, militante feminista y anarquista, el contraste entre su clase social tras su unión con Botana y su postura ideológica motivaron su imagen de "descentrada", que, en los textos críticos y biográficos, se resume habitualmente en la referencia de su llegada a los actos sindicales en un Rolls Royce.

Como explica Sylvia Saítta (2012), Medina Onrubia, nacida en la ciudad de La Plata, comienza su labor periodística, muy joven, en El Diario de Gualeguay de la provincia de Entre Ríos, en donde se desempeñaba como maestra en una escuela rural (párr. 2). Con veinte años y siendo madre soltera de un hijo varón, se establece en Buenos Aires y, a partir de allí, su vida estará

\footnotetext{
${ }^{3}$ Contamos con reseñas de los siguientes periódicos: Crítica, Noticias Gráficas, El Diario, La Vanguardia (de Buenos Aires), El Diario Español, El Mundo (de Buenos Aires), El Pueblo, La Prensa, La Razón, Última Edición, Orientación y Argentinisches Tageblatt.

${ }^{4}$ Destacamos la publicación de la novela Salvadora. La dueña del diario Crítica de Josefina Delgado, publicada en 2005; la reedición, en 2007, de las obras de Medina Onrubia La solución, Las descentradas y Un hombre y su vida en la colección "Los Raros" de Ediciones Colihue y la Biblioteca Nacional argentina, con prólogo de Delgado; la puesta en escena de la obra teatral Rabia roja. Letra viva de Salvadora Medina Onrubia, de Maruja Bustamante, en el Teatro San Martín de Buenos Aires en 2017, como parte del "Ciclo de Mercurio"; el estreno, también en 2017, del documental Salvadora, dirigido por Daiana Rosenfeld; y la exposición sobre el periódico Crítica en la Fundación OSDE entre noviembre de 2015 y enero de 2016, en la que se le dio un espacio importante a la figura de Salvadora.
} 
marcada por una serie de acontecimientos relevantes para la comprensión de su figura.

En la ciudad, por ejemplo, Medina Onrubia comienza a militar en el anarquismo y, en este contexto, se destacan dos momentos: por un lado, su muy referida amistad con el obrero anarquista ruso Simón Radowitzky, su intervención en los intentos de fuga de este tras el atentado contra el jefe de Policía Ramón Falcón durante la "Semana Roja" de 1909 y su gestión ante el presidente Hipólito Yrigoyen para que fuera indultado; por el otro, su presencia en un mitin organizado por la Federación Obrera de la República Argentina (FORA) en 1914, cuando pronuncia un discurso contra las leyes de represión y por la libertad de los presos anarquistas. Es esta una lucha que continuará desde las páginas del periódico La Protesta, al que se suma como redactora un par de días después de este evento y a través del cual, asimismo, escribirá a favor de los derechos de la mujer (Ver Saítta, 1995: párr. 2 y Saítta, 2012: párr. 1 y 2). También en 1914, estrena su primera obra teatral, Almafuerte, con la que da inicio a su trayectoria literaria y, poco tiempo después, conoce a Botana, quien le dará su apellido a su primer hijo y con quien se casará en 1919, tras el nacimiento de sus tres hijos en común. Es en ese momento cuando comienza a construirse la imagen de una mujer que se aleja del paradigma femenino social y culturalmente aceptado en las primeras décadas del siglo XX (Saítta, 1995: párr. 2).

Su carrera literaria y periodística irá en ascenso, pero también su compromiso político. En este sentido, protagonizará, junto a Botana, un episodio resonante ante la clausura de Crítica en 1931 -al año siguiente del golpe de Estado de 1930 de José Félix Uriburu contra el gobierno de Hipólito Yrigoyen-, que los llevó a ambos a la cárcel. Desde entonces, Medina Onrubia se enfocará en el periodismo y en la política como miembro fundadora de la agrupación feminista "América Nueva" y militante en favor de los derechos civiles y políticos de la mujer, como el derecho al sufragio y a la igualdad ante la ley (Saítta, 2012: párr. 7). Como vemos, en palabras de Saítta (2012),

[s] biografía narra entonces varias historias: la historia exitosa de quien supo ser la mujer de Natalio Botana, el director del poderoso diario Crítica con quien se casó 
después del nacimiento de sus tres hijos [y a quien reemplazará en la dirección del periódico tras su muerte en 1941]; la trágica historia de una madre soltera, cuyo primer hijo se suicidó a los veinte años cuando supo que su padre no era Botana sino algún otro; la historia de una mujer que encontró en la literatura, el periodismo y el teatro los ámbitos en los cuales expresar su desasosiego frente a una sociedad que aun modernizándose a ritmos acelerados, mantenía, con respecto a las mujeres, leyes, prejuicios y protocolos provenientes de un pasado remoto (párr. 1).

Medina Onrubia escribió cuentos (La casa de enfrente, 1926), una novela (Akasha, 1924), poemas (La rueca milagrosa y El misal de mi yoga, 1929) y obras teatrales (la mencionada Almafuerte, La solución, Las descentradas, Un hombre y su vida...).

\section{Un hombre y su vida: una lectura argentina de la Guerra Civil Española}

Considerada una autora excéntrica dentro del panorama teatral de los años 30, según Josefina Delgado (2007), precisamente, "es en los textos teatrales donde puede percibirse una voz atractiva; y también retazos de sus experiencias, a veces, mal digeridas pero siempre introduciendo una visión de mundo diferente" (20). Así sucede, plantea, en Un hombre y su vida, obra con la que Medina Onrubia cierra su escritura ficcional y en la que muestra una lúcida comprensión del problema de las revoluciones, a solo un mes del inicio de la Guerra Civil, en 1936 (Delgado, 2007: 21).

Aunque escribió esta pieza en tres actos y cinco cuadros inspirada por esa contienda, subyace una reflexión sobre Europa en las tres primeras décadas del siglo XX. Delgado (2007) menciona el interés de Medina Onrubia "por un teatro que pudiera iluminar los problemas de una sociedad moderna" (22) y eso se vislumbra en Un hombre y su vida. Incluso más: podríamos hablar de convicción, si pensamos no solo en el contexto de producción, sino también en el momento elegido para llevarla a escena por primera vez.

Para entonces, como comentamos, Buenos Aires tenía una intensa vida cultural que reunía grandes nombres de españoles que apoyaban la causa republicana: Margarita Xirgu, Manuel de Falla, Gori Muñoz, Gonzalo Losada, entre otros (Ver Schwarzstein, 1999: 128; Diago, 1994 y 2006). En el ámbito teatral, aunque la mayor parte de los actores y dramaturgos españoles exiliados en la Argentina se declaraban neutrales o apolíticos para no perder 
posibilidades laborales, lo cierto es que se vivió la misma división ideológica que se advertía en la sociedad, pero los partidarios de ambos bandos convivían (Diago, 1994: 3; 1995: 207; 2006: 82). La Guerra Civil se transformó en el tema de algunas pocas piezas y fue tratado directa o indirectamente y desde diferentes perspectivas, pero fue Un hombre y su vida la que suscitó mayor interés dramático que otras (Diago, 2006: 85; ver también Binns, 2014: 31), debido a "una mayor enjundia literaria y a una especial sensibilidad femenina" (Diago, 1995: 213).

El programa de la primera función data el estreno de la obra el 10 de marzo de 1939, pocas semanas antes del fin de la contienda, en el Teatro Maravillas de Buenos Aires y por la Compañía Española de Comedias, encabezada por los primeros actores Helena Cortesina y Pedro López Lagar. Para ese entonces, ambos eran ya muy conocidos y aplaudidos por el público y la crítica; y la dirección artística estaba a cargo del también celebrado periodista, escritor, comediógrafo y director español, nacionalizado argentino, Gerardo Ribas ${ }^{5}$. Probablemente, junto con el de Medina Onrubia, ya valorada como dramaturga, los nombres de los artistas españoles (Cortesina y López Lagar, muy especialmente) fueron una de las razones del éxito de la pieza que se mantiene en cartel durante casi un mes (hasta el 7 de abril) -, según se desprende de las reseñas del estreno incluidas en periódicos de la época de distinta tendencia ideológica:

\footnotetext{
${ }^{5}$ Helena Cortesina (Valencia, 1904 - Buenos Aires, 1984) fue bailarina y actriz de teatro y cine, directora y productora cinematográfica en su propia empresa, Cortesina Films (1922), roles estos últimos que la destacan en su época. Integró, asimismo, las compañías de Gregorio Martínez Sierra y de Lola Membrives, y formó la propia junto al actor Andrés Mejuto, también exiliado y exintegrante de la compañía de Margarita Xirgu. Se une, luego, a Pedro López Lagar. Pedro López Lagar (Madrid, 1899 - Buenos Aires, 1977) fue un importante actor que se desempeñó, durante su estancia en la Argentina, en cine, radio y teatro y con gran éxito, como lo evidencian las numerosas reseñas, las notas y las entrevistas incluidas en la prensa de la época.

En 1938, crea su propia compañía, dirigida por Samuel Eichelbaum, con la que estrena Tierra dura, del periodista y escritor gallego Xavier Bóveda (1898-1963), residente en la Argentina desde 1923. En 1939, crea la Compañía Española de Comedias, que se presenta con el estreno de Un hombre y su vida y que, en ese mismo año, pone en escena Galicia Madre o el emigrante, de Bóveda, que protagoniza junto a Cortesina.

Gerardo Ribas (Madrid, 1907 - Buenos Aires, 1981) llegó a la Argentina a los 50 años, desarrolló una importante carrera, integró la Comisión Nacional de Cultura y llegó a ser directivo del Comité de Argentores.
} 
La concurrencia aplaudió entusiastamente en diversos pasajes de la obra, y al final requirió la presencia de la autora y del director Gerardo Ribas (Noticias Gráficas).

Los aplausos que saludaron el comienzo de la interpretación, se repitieron a lo largo de la pieza y se hicieron más insistentes, si cabe, al final, requiriéndose la presencia de la autora y los primeros actores (El Diario).

Un público tan numeroso como adicto llen[ó] la sala, y no se mostró parco en sus demostraciones hacia la autora, sus intérpretes y la tendencia ideológica de la pieza. [...] Al terminar la representación, la señora Medina Onrubia fué [sic] llamada a escena, debiendo hablar en público. También [l]o hicieron e[l] director y las dos primeras figuras del elenco (La Razón).

Gracias a las reseñas, ya que no aparecen en el programa, sabemos también que los decorados estuvieron a cargo del escenógrafo Armando Coli, de origen italiano y nacionalizado argentino, y los vestuarios, de la pintora, figurinista, escenógrafa, diseñadora y escritora española, también exiliada, Victorina Durán, ambos ya famosos y elogiados por la crítica (Ver la reseña de Carlos H. Faig aparecida en Crítica) ${ }^{6}$. Por último, según el programa, la puesta contaba con la actuación, en el segundo acto, del también famoso y exiliado cuarteto de laúdes Aguilar, liderado por Paco Aguilar, destacado siempre en las reseñas (Ver las reseñas de Carlos H. Faig en Crítica; de Jaime en La Vanguardia, de Última Edición y de Juan Cronista en Orientación).

\section{La discusión sobre la pertinencia del tema}

En pocas líneas, Un hombre y su vida sigue los pasos de su protagonista, el español Álvaro de Iratche, en tres momentos de la historia: en

\footnotetext{
${ }^{6}$ Armando Coli (Pescara, 1887 - Buenos Aires, 1967) llegó a Buenos Aires en 1908, contratado para la puesta en escena de la ópera Aída, con la que se inauguró el Teatro Colón, y adquirió la ciudadanía en 1910. Realizó la mayor parte de su trabajo en la Argentina con las grandes compañías nacionales, como la de Lola Membrives, y con las extranjeras que pasaban por el país (Zayas de Lima, 1990: 76).

Victorina Durán (Madrid, 1899-1993) se formó junto a Salvador Dalí y Maruja Mallo. Formó parte de la innovadora compañía TEA de Cipriano Rivas Cherif y de la compañía de Margarita Xirgu. Con ella se exilió en la Argentina en 1937, donde contó con el apoyo de Botana y de Medina Onrubia. Llegó a ser directora del Teatro Cervantes y del Teatro Colón en Buenos Aires. Volvió a España en 1963.

En 2018, la Residencia de Estudiantes de Madrid presentó la edición de sus memorias en tres tomos, a cargo de Idoia Murga Castro y Carmen Gaitán Salinas.

Para más información sobre Durán ver Eva María Moreno Lago (2018). "Transitar dos mundos: inventario teatral de Victorina Durán", Acotaciones (enero-junio 2018), 40, pp. 15-38; específicamente, las páginas 47-53 para una referencia a su participación en esta puesta en escena.
}

Diablotexto Digital 8 (2020), 127-153 
1906 ("El pasado del hombre") en el barrio latino de París, como infiltrado en un grupo de refugiados rusos, cuando logra desarmar su complot contra el régimen zarista; Sonia, una de sus miembros y su amante, se suicida al saberlo un traidor y ante su debilidad para delatarlo; en 1930 ("La vida del hombre") en la embajada de España en París, casado, duque de Torrelodones y exembajador de España en Estados Unidos, admirador de Hitler y Mussolini, cuando, ya caído Primo de Rivera, en el último tramo de la Restauración borbónica, se vislumbra el advenimiento de la Segunda República; y, finalmente, en 1936 (“El hombre: el mismo”), apenas iniciada la Guerra Civil, en el cuartel de Granada, como general del Ejército sublevado, que, junto al coronel del Llano, ha tomado prisionero y tortura a un grupo de españoles leales que transmiten noticias por una radio clandestina ${ }^{7}$. La vida de Iratche estará marcada por el espectro de Sonia, que se encarnará en María Victoria, integrante del grupo preso. Su parecido físico y sus palabras, idénticas a las de Sonia antes de su suicidio ("algún día tú comprenderás") 8 , son, para Iratche, una epifanía, que lo lleva a liberar a los presos y a suicidarse.

La obra suscitó más de una polémica no tanto por su factura artística (que también fue discutida), cuanto por el tema elegido, por su contenido ideológico y por el momento de su estreno, cuando el triunfo de las fuerzas sublevadas sobre las republicanas era claro y su anuncio, inminente: mientras algunos le reprocharon el adentrarse en un asunto delicado para la comunidad española, otros, por el contrario, aplaudieron la sagacidad de su perspectiva.

El anónimo autor de la tibia reseña aparecida el 11 de marzo (s/p.) en el periódico La Nación -de tradición conservadora y liberal-, por ejemplo,

\footnotetext{
7 ¿Una alusión al general Gonzalo Queipo de Llano? Llegó a tener pleno control sobre Andalucía y era muy famoso por su afición a la radiofonía. En la Argentina, ante la posibilidad de su llegada, se debatió en el Congreso considerarlo "persona no grata" (Ver las siguientes notas periodísticas: Crítica, 27 de julio de 1939, p. 4, y 28 de julio de 1939, p. 5).

${ }^{8}$ Le dice Sonia a Iratche: "Eres puro porque eres inconsciente" (173); "Ésa [sic] es la clave. Comprender. La humanidad que comprenda será dueña de esta tierra de todos... [...] Y algún día tú también comprenderás... Llegará a ti algo... Dentro de ti algo madurará... Y comprenderás. El secreto está sólo [sic] en comprender... Tú comprenderás. Grábatelo, Álvaro: COMPRENDERÁS. Mírame bien mi cara, Álvaro... Mírame. Un día comprenderás..." (175-176; mayúsculas sostenidas en el original). Y María Victoria le dice: "Usted es puro. Algún día usted comprenderá... ¡Oh, yo sé que usted comprenderá!... Algo en usted madurará...". "Ya he comprendido - responde Iratche-. [...] Sonia, he comprendido" (245).
} 
considera el tema del último acto "poco oportuno en estos días dolorosos para el pueblo español, y acaso también inconveniente desde el momento en que se particulariza demasiado". El también anónimo autor de la reseña del 12 de marzo publicada en El Diario Español (s/p.), profranquista, coincide en este punto. Lapidario en su análisis ideológico y literario de la obra desde el inicio, califica peyorativamente la obra de "apasionada apología" del comunismo: "nos parece inoportuna, a destiempo, en estos momentos tan de pena y de dolor para los españoles todos, de todas ideologías, y sobre todo muy tendenciosa y partidista, puesto que toda ella, como se ha dicho, no es en el fondo sino un canto en honor y loor del comunismo".

El autor de la reseña de La Nación, entonces, elige centrarse en la "factura literaria", resaltada ya en el título, y no en la cuestión de fondo, política, indicio de su conservadurismo: "Si no se toman en cuenta su tema actual y los aspectos políticos que presenta, adviértese en «Un hombre y su vida» una idea interesante a la que se ha dado con frecuencia relieve dramático: el retorno del pasado, su consecuencia en el presente y su proyección en lo futuro". Este recurso de generalización y abstracción, que despoja la obra de su contenido ideológico, continúa: "Es una idea que Salvadora Medina Onrubia ha envuelto en la figura poética de una mujer, en la que ha simbolizado, no solo la continuidad de la vida, sino la marcha ineluctable de la humanidad, dentro del desenvolvimiento y la orientación que juzga seguros y convenientes la autora". Similar idea aparece en la reseña del 11 de marzo en La Prensa (s/p), cuyo anónimo autor describe de manera ligera a Sonia como un personaje que "habla con espíritu filosófico de la condición humana".

En la línea de estas ideas se expresa el también anónimo autor de la reseña del periódico La Razón del 11 de marzo (s/p.): alude a personajes sin identidad y los define como "entes representativos de las tendencias en pugna", "sólo [sic] voceros de la autora, ajenos a toda preocupación de tiempo y teatralidad", menospreciando las ideas que transmiten y abordando la obra como teatro de tesis. También se refiere de manera peyorativa al "tono oratorio" de su "héroes" - "nacionalistas y gubernistas", términos que revelan la postura del autor frente al conflicto- y a sus parlamentos, "tiradas 
extensísimas, documentadas y elegantes, propias de una tribuna de ateneo". Crítico de la factura de la pieza, señala que "[l]a señora Medina Onrubia, escritora de sólido nombre, no ha sentido, o no ha concedido importancia a la preocupación lógica de hacer teatro", idea que se repite a lo largo de toda la reseña. Más adelante, sostiene que "[l]a satisfacción íntima de hacer decir a sus personajes lo que ella siente, malogra su esfuerzo de autora"; y, finalmente, califica de "lastre fatal" el tono discursivo de la obra para culminar diciendo que es una de esas obras que "ganan leyéndolas".

Asimismo, en esta reseña, es preciso reflexionar sobre el silencio y las insinuaciones respecto del tema de la pieza, que se une a la crítica a la autora:

\footnotetext{
Evitamos narrar su asunto, muy complejo, y que gira en torno del dolor de España. Es España un sujeto experimental para la señora Onrubia, que, operando sobre su drama, desarrolla sus puntos de vista y enfrenta las dos fuerzas políticas y sociales únicas, que, a su juicio[,] gravitan hoy sobre la marcha de la humanidad, y que la autora, enemiga de eufemismos, dice claramente: Roma y Moscú.
}

Con cierta contradicción, en el final, destaca, entre los méritos de la pieza, "la visión amplia del panorama universal" y "sus anhelos, vehementemente expresados por una organización social edificada sobre cimientos más generosos y equitativos". Se trata de una reseña atravesada por lo no dicho y por algunas paradojas: no ataca directamente la postura ideológica de su autora ("respetable como todas siendo sincera", dirá), pero critica "sus frecuentes latiguillos, tan anacrónicos como de seguro efecto"; y, luego, aplaude "sus intenciones de dar a la comedia visos de equidistancia en su visión del pleito español”, interpretación que se aleja de la postura de Medina Onrubia.

Una mirada interesante es la de W.K. en su reseña publicada el 24 de marzo en el Argentinisches Tageblatt (s/p.), periódico en lengua alemana fundado en Buenos Aires en 1874, de origen liberal, que, en la época que nos ocupa, mantenía una posición antinazi ${ }^{9}$. El autor encuentra en Un hombre y su vida una visión lúcida del problema español en el contexto europeo. En primer lugar, califica la obra de "verdadero Zeittheater", cuya traducción sería,

\footnotetext{
${ }^{9}$ Agradezco a Jorge Rauber la traducción de esta reseña. 
literalmente, "teatro-tiempo", y que se definiría como un teatro que trata temas crudos, problemas candentes en forma casi documental, auténtica:

Salvadora Medina Onrubia ha evitado escribir una acción cualquiera en el contexto de la Guerra Civil española, sino que toma, valiente y noblemente, la presentación de la Guerra Civil española hasta sus últimas consecuencias, y la vida de su héroe Álvaro de Iratche da, en definitiva, el marco para esta clara y abierta postura.

Y detalla, oponiéndose a más de una de reseña:

Lo más señorial sobre este Zeittheater: la abundancia de pensamientos que transmiten con gran precisión, de diálogo en diálogo, una imagen real de la España actual y futura. "Un hombre y su vida" es importante, por lo tanto, en estos momentos de inseguridad general, debido a la claridad de su noble lenguaje porque aquí, sobrio, sin ningún falso optimismo, se muestra un camino.

Para W.K. es una obra con "una audiencia entusiasta y que no solo busca un entretenimiento superficial en el teatro" (s/p.) y encuentra, en las palabras de Sonia/María Victoria, "la determinación de la raza humana, la idea de la eterna lucha por la libertad"10.

La polémica, entonces, tiene su eje, más o menos explícitamente, en torno de cuestiones político-ideológicas, que incluye la evaluación de la lectura de la Guerra Civil subyacente en la pieza, y también morales, como veremos. Pero, asimismo, confluyen la valoración de Medina Onrubia como escritora y de su obra, todos aspectos muy vinculados entre sí y que, en ocasiones, se determinan. Veamos algunos ejemplos.

\section{Medina Onrubia y su obra en Crítica}

Entre los periódicos que se identificaban con el planteo ideológico de Medina Onrubia, como sabemos, se encuentra Crítica, que asumió en sus páginas la defensa de la República Española, el "gobierno del pueblo" (ver la reseña de Carlos H. Faig), y que, además, era la "casa" de la autora. Por esta razón, puede parecer ocioso el acercamiento a su apreciación de la obra. Sin embargo, justamente por ello, es el medio que nos proporciona más

\footnotetext{
${ }^{10}$ En otro orden de ideas, una llamativa referencia al contexto: el autor afirma que "[a]l hablante alemán también le da la representación de esta obra una valiosa oportunidad para mejorar sus habilidades lingüísticas y familiarizarse con un entorno que se puede encontrar aquí en vista de la fuerte influencia española en Argentina". 
información sobre la recepción de Un hombre y su vida, su vinculación con la red de contención a los exiliados y el lugar que ocupó en los debates sobre la Guerra Civil en una sociedad dividida. Y lo hace no solo a través de las reseñas, sino también de los avisos publicitarios y de breves notas que ofrecen información sobre el lugar que ocupó la pieza en el marco de eventos en apoyo a la República española y a los exiliados.

Carlos H. Faig, en su reseña del 11 de marzo (s/p.), define Un hombre y su vida como

el primer alegato escénico de carácter histórico que en nuestra habla se haya hecho del extraordinario movimiento que ha removido el limo español, haciendo fermentar lo que en su estallido se intentó evitar: la revolución de conciencias, precisamente. Y tiene especial significado que sea una mujer quien se atreva a decir palabras claras y terminantes, valientes y calientes de vida en este oscuro momento del mundo.

En Crítica, no extraña el panegírico a la figura Medina Onrubia, incluso como representante del género femenino, que continúa más delante de manera encendida y que se entrelaza, por un lado, con la mirada del periódico respecto de la Guerra Civil en el contexto europeo y, por otro, con la crítica a la falta de compromiso de muchos hombres:

\begin{abstract}
Ahora que tantos hombres esquivan con su silencio la responsabilidad de una actitud; cuando, frente a la masacre, esos hombres cubren sus ojos, taponan sus oídos y afinan el metal de la voz, para evitarle asperezas al grito de indignación a que están obligados; en el momento en que una raza, que es la nuestra, porque la llevamos en cada gota de nuestra sangre, comienza por el mundo su peregrinaje de perseguida [...]; en este instante, que es nuestra época, cobra especial significación la palabra de la mujer. [...] La mujer es la guardadora de la especie. Mientras ella aliente, y sufra, y nos haga llegar el sentido de su rebeldía, nos quedará siempre la esperanza del nacimiento de locos geniales que hablen de una edad feliz. Aunque los Sanchos, a su lado, callen y coman bellotas.
\end{abstract}

En las puertas de la inminente Segunda Guerra Mundial, de la era de los exilios y del silencio cómplice de muchos "Sanchos", no es casual que Faig hable de un "alegato histórico". Tampoco que subraye la importancia de la obra y de su autora, "Madre" que da a luz a "don Quijotes", una imagen estereotípica de la mujer-Madre, tan propia de la época, que resulta paradójica en referencia a una figura como Medina Onrubia aunque aquí se utilice para resaltar su valía. O que identifique, por último, al pueblo argentino con el español, hermanos de sangre, recurso muy habitual, como veremos, en los avisos publicitarios. 
Las referencias posteriores al 11 de marzo en el periódico Crítica refuerzan esta primera reseña. En el aviso de promoción de la pieza del 14 de marzo (p. 2), se define el espectáculo como un "gran éxito teatral" y, nuevamente, como "un alegato sin precedentes", "una comedia que todos deben ver", "no sólo [sic] para los españoles, es para todos"; una obra en la que hay "corazón y sentimiento". Asimismo, se resaltan las cuatro "cabezas" de ese éxito con sus nombres y sus fotos en el aviso: Helena Cortesina, Pedro López Lagar, Pablo Vicuña y Eduardo Casado (figura 1). En el del 17 de marzo (p. 4), se apela a una estrategia más efectista: se incluye, por un lado, una foto de una escena del tercer acto - definida como "una de las más vigorosas"-, con Pedro López Lagar y Pablo Vicuña en los roles de los militares sublevados, general Iratche y teniente Alisedo respectivamente, frente al mapa de España; y, por el otro, un extracto de su tenso diálogo, que es elocuente del armado del bando liderado por Francisco Franco (figura 2). Dos días después, en el aviso de las primeras veinte representaciones del "drama histórico español", destaca el título "Españoles 100 x 100", sumamente significativo en este contexto, referido a los actores protagónicos, cuyas fotos ilustran la publicidad. Se anuncia una función especial dedicada al Centro Republicano Español y a la Federación de Sociedades Gallegas, con la presencia de Medina Onrubia y del director Gerardo Ribas, lo cual subraya la importancia del evento y su apoyo a los leales a la República (figura 3). A igual estrategia fotográfica apela el anuncio del 25 de marzo (p. 2): en este caso, la imagen de los personajes principales precedida por la frase "expresan el pensamiento de la España de hoy" y seguida, al pie, por "la comedia que alienta todo buen español" (figura $4)^{11}$.

\footnotetext{
${ }^{11}$ Ver el aviso de la Cámara de Comercio de la República Española y el breve texto sin firma del 26 de marzo, p. 13; también la nota del 27 de marzo, p. 7, y el aviso del 28 de marzo, p. 4. 


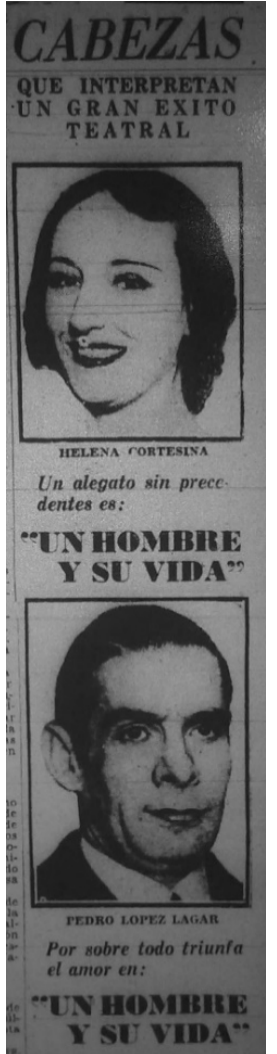

Fig. 1. Crítica, 14-3-1939, p. 2.

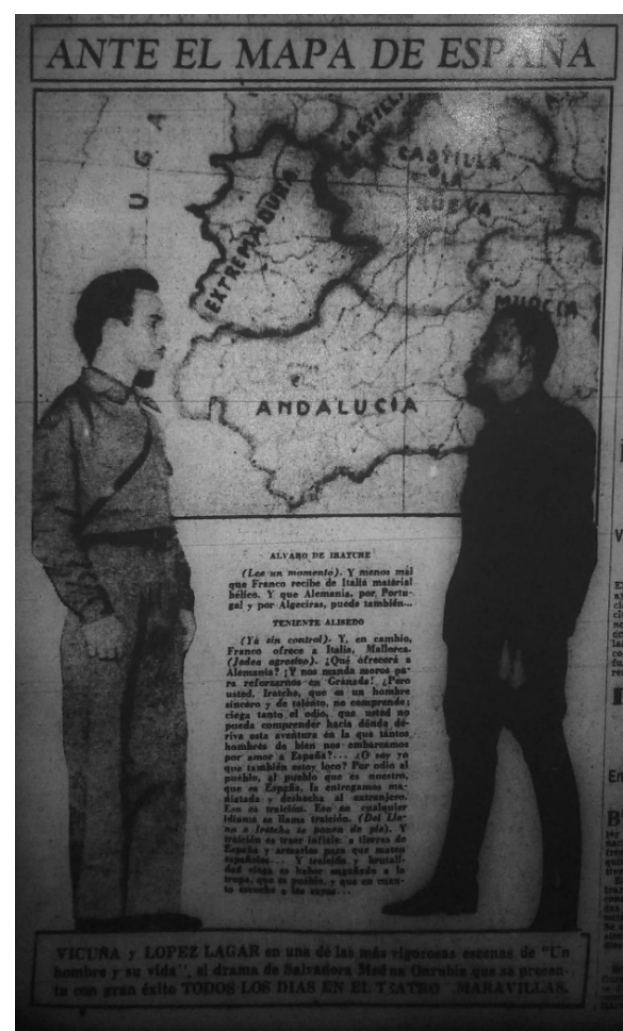

Fig. 2. Crítica, 17-3-1939, p. 4.

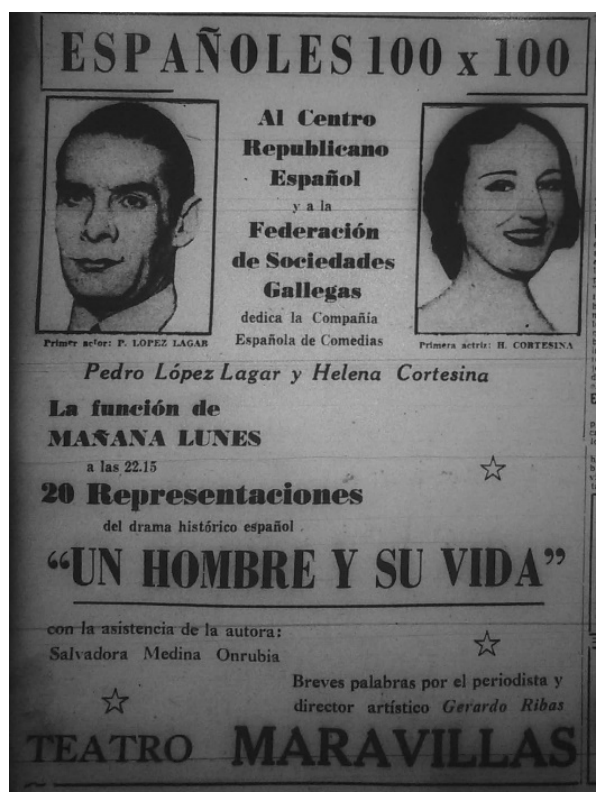

Fig. 3. Crítica, 19-3-1939, s/p.

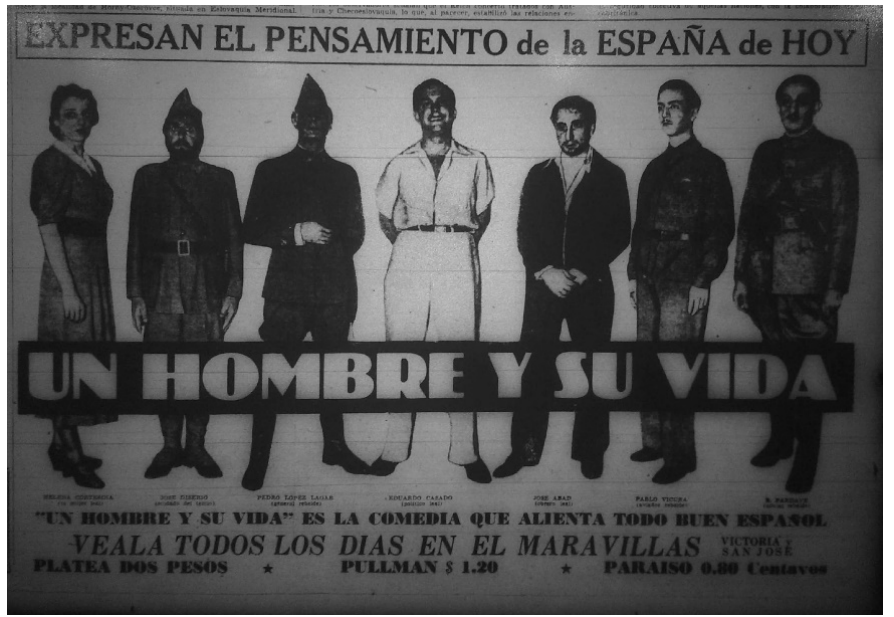

Fig. 4. Crítica, 25-3-1939, p. 2.

El aviso de la función número cuarenta y cinco, el 1 de abril, día que se notifica el fin de la Guerra Civil, se construye sobre una foto de un hombre mirando fijamente al frente y señalando la exclamación "¡ATENCIÓN!" (figura 
5). Publicita la obra, acorde al momento, como "[u]na voz de aliento para todo buen español" y "[u]na palabra de estímulo para todo hombre libre"; y, además, anuncia "la extraordinaria velada" del 5 de abril, "el gran festival en conmemoración de las 50 representaciones dedicado a las sociedades españolas", en el que participarán "varias figuras descollantes del teatro argentino", lo cual da cuenta de esa red de apoyo y contención que señalábamos (p. 4). Según los avisos del 3 (p. 10; figura 6), del 4 (p. 4; figura 7) y del 5 de abril (p. 4), cuando se incluye también una breve nota (p. 10), los artistas participantes fueron Libertad Lamarque, "la reina de la canción porteña", quien cantó "algunas de sus populares canciones"; Claudio Martínez Payva, "celebrado autor y escritor argentino", que hizo "uso de la palabra" para referirse "a la importancia y trascendencia de «Un hombre y su vida» y a la significación que debe asignársele en el enfoque de la cuestión española"; Luis Arata, "popularísimo primer actor del teatro de Par[í]s", quien ofreció "uno de sus mejores monólogos"; Fernando Ochoa, "festejado actor del Teatro Astral", que recitó "su mejor repertorio" de poemas; y Marcos Caplán, que refirió "anécdotas y pasajes festivos".

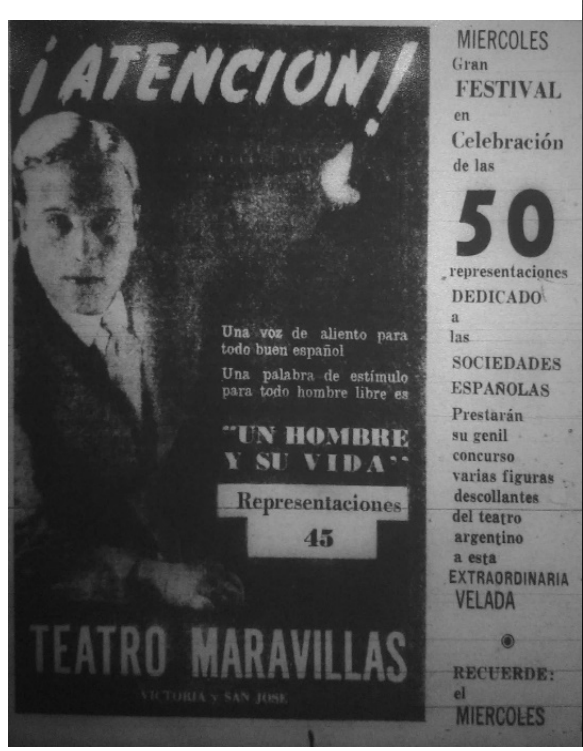

Fig. 5. Crítica, 1-4-1939, p. 4.

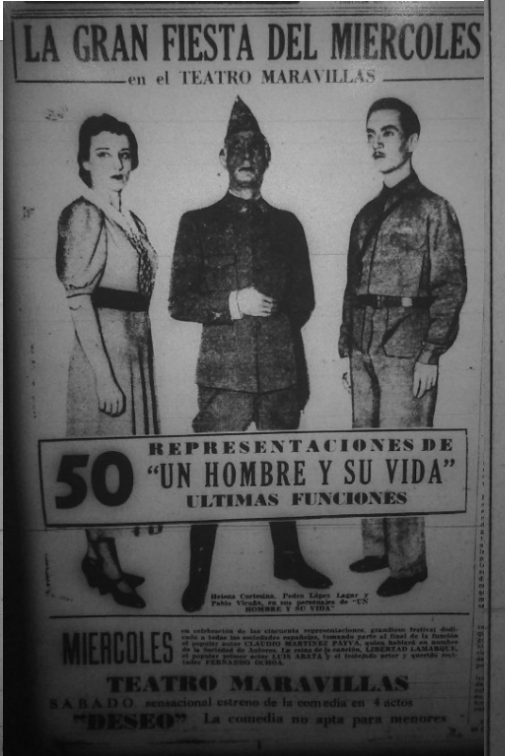

Fig. 6. Crítica, 3-4-1939, p. 10.

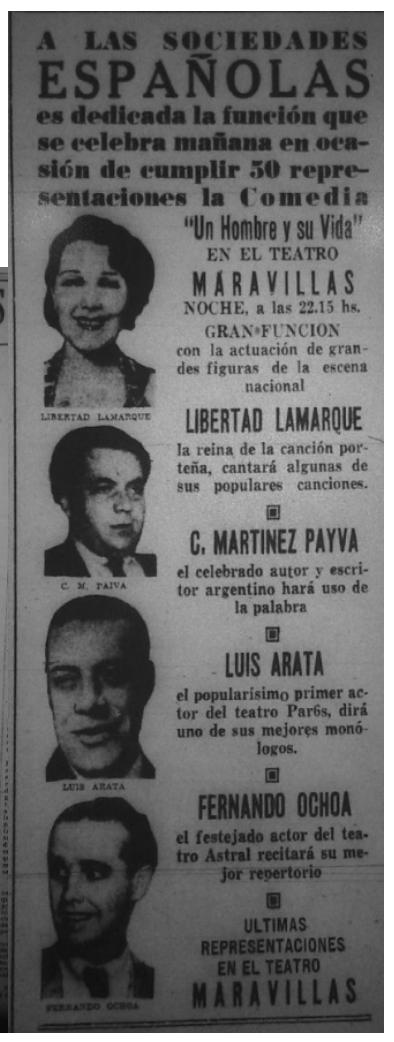

Fig. 7. Crítica, 4-4-1939, p. 4. 


\section{El apoyo en Orientación, Última Edición, Noticias Gráficas y El Diario}

El valor de Medina Onrubia y su obra es también destacado por Juan Cronista $^{12}$ en su reseña del 16 de marzo, publicada en el periódico del Partido Comunista Orientación (s/p.). Identificado con el planteo ideológico de la pieza, en el título, califica la obra de "valiente y eficaz" y, en el cuerpo del texto, a pesar de que señala fallas técnicas, la describe como "vibrante, vigorosa y positiva". Pero uno de los aspectos más importantes es que subraya su "doble valor, por tratarse de una mujer que sabe decir con hermosas palabras su mensaje; una valiente mujer de nuestra época que, como las protagonistas de su pieza, sabe de la fe, de la lucha y de la esperanza”. Juan Cronista resalta, entonces, la figura de la autora como militante y su mensaje de la batalla por el hombre nuevo, que hace recaer en Albornoz, estudiante de derecho, y en María Victoria, "un espíritu nuevo, firme, valiente", personajes del tercer acto: "[...] los dos jóvenes leales son [...] el prototipo de la nueva juventud. El nuevo hombre y la nueva mujer que trabajan estrechamente unidos -identificadostanto en los bancos de las universidades por una nueva cultura, como en los puestos de combate por una nueva humanidad".

En esta misma línea, aunque con un discurso algo eufemístico, se sitúa Rep [?] $]^{13}$, autor de la reseña aparecida en el periódico Última Edición el 12 de marzo (s/p.). Hace referencia clara al contexto histórico y al contenido ideológico de la pieza e interpreta la postura de Medina Onrubia: "La autora ha sorteado con habilidad literaria los muchos riesgos de una obra, en la que se entrechocan idearios tan opuestos como los que van de Roma o Berlín a Moscú, si bien trasciende con evidencia de qué lado están sus simpatías”. Los personajes son abordados como encarnación de las ideas en conflicto en el mundo de entonces, "[...] el símbolo y la representación de la crisis social que, apuntada en los primeros años del siglo, estallaría en la gran guerra con su secuela trágica de los días presentes"; pero también como portadores de un mensaje esperanzador para todos los hombres. Carlos H. Faig, en su reseña,

\footnotetext{
${ }^{12}$ Un nombre que consideramos un seudónimo, una forma de enmascaramiento identitario.

${ }^{13}$ El perfil de las letras aparece incompleto.

Diablotexto Digital 8 (2020), 127-153

doi: $10.7203 /$ diablotexto.8.17685
} 
depositaba este mensaje en el suicidio de Iratche, interpretado como un gesto de integridad, "síntesis de la raza" española, cuando se produce "el encuentro del hombre con su alma" y "comprende, es él mismo; se ha encontrado sin buscarse; es su conciencia que fluye en oleaje impotente y lo arrastra todo [...]"; finalmente, "[c]uando un español, luego de una vida equivocada comprende, se da un pistoletazo" (negritas en el original).

En la reseña del estreno, Noticias Gráficas (s/p.), periódico de un izquierdismo moderado que apoyó a la República española durante la Guerra Civil, evidencia su adhesión a los planteamientos de Medina Onrubia desde el inicio. El anónimo autor reconoce el "digno propósito" que presidió la realización de la obra, "impropiamente calificada como comedia", a la que presenta como "una exposición interesante de las causas y prolegómenos de la contienda española", llevada por el "criterio certero" de su autora. Aunque, continúa, ello la lleva a ser "una producción de neto corte político, polemista y doctrinario, apartándose de las tradiciones que particularizan al verdadero teatro" - de allí que la califique de "pieza panfletaria" en el título-, no desmerece a la autora, a quien atribuye "un talento original y una pluma firme y vibrante". Los términos "leales" y "facciosos" para mencionar a los republicanos y a los sublevados, respectivamente, y -en la referencia al diálogo de los diplomáticos del segundo acto- el entrecomillado de "peste roja", signo de distanciamiento respecto de la expresión, afirman la posición.

Como en la reseña de Crítica y en la de El Diario, habrá también una invectiva contra los diplomáticos españoles, ajenos a la realidad, que se alinean contra la "peste roja"; asimismo, se subraya la lectura contextual de Medina Onrubia sobre la Guerra Civil en el tercer acto - "[s]e historia en ese cuadro la No Intervención, la invasión de los moros, la ayuda ítalo-germana y la ceguera creciente de los facciosos en la solución del problema de España" - y se destaca la "epifanía" de Iratche como un mensaje al mundo: su muerte es la esperanza de que otros comprenderán y de que el futuro será mejor para la humanidad. 
El autor de la reseña del 11 de marzo incluida en El Diario (s/p.), periódico de izquierda, califica la obra como "drama histórico" con unidad de ideas y propósitos y cuya preocupación es la libertad y el derecho del pueblo:

[...] sólo [sic] bastaría el tema histórico elegido para colocar la nueva producción de Salvadora Medina Onrubia entre los mayores acontecimientos literarios del año que se inicia. La dramática nacional no conoce casi la comedia histórica. Fuera contadas y convencionales evocaciones de la Colonia y la Tiranía, el teatro argentino se ha desentendido de los hechos que afectan la estructura total de la sociedad. Característica del pueblo nuevo que no ha logrado fijar aún sus rasgos sustantivos.

Aunque se considera la calidad literaria de la obra en la reseña, como vemos, fundamentalmente, se resalta su importancia en el contexto político del estreno en una elocuente crítica no solo al teatro, sino a la sociedad argentina.

\section{La Vanguardia (de Buenos Aires), El Pueblo y El Diario Español: periódicos antagónicos unidos por el rechazo}

El periódico La Vanguardia (de Buenos Aires), vinculado al partido socialista, hablará de la "tragedia de la vida" de Iratche, que es la de España y la del mundo:

Treinta años que abarcan los grandes acontecimientos histórico-sociales que han sacudido al mundo en un dantesco callejón cuya salida no puede vislumbrarse aun y en el cual dos clases sociales se debaten por imponer sus legítimas reivindicaciones la una; su concepción oscurantista del derecho humano la otra (s/p.).

De allí que al autor, que firma simplemente como Jaime, no le parezca suficientemente clara o comprometida la postura de Medina Onrubia y que plantee que no es posible aceptar una posición equidistante o imparcial sin caer en una "inane invocación mesiánica de concordia imposible". Un hombre y su vida es, para Jaime, "una pieza de teatro político", aunque su autora no haya tenido esa intención, dice, y, por el contrario, en lugar de "un grito de combate", propusiera "una canción por la paz y la confraternidad". Pero "la realidad política, viviente, tangible" y sus protagonistas (Franco, Hitler, Mussolini, Lenin, Stalin) se imponen, de manera que la tragedia de Iratche no puede desligarse fácilmente del contexto. Por ello, afirma, no puede aceptarse la ambigüedad que, desde su perspectiva, caracteriza la obra y que ejemplifica con un análisis lapidario de cada acto. 
Jaime seguirá subrayando la vaguedad y abstracción de la obra cuando se refiera al segundo acto: "Nada de plantear el desenlace de la obra, situando la guerra española en su proyección europea”. Esta última apreciación debe ser destacada porque se vislumbra la percepción de la Guerra Civil Española como un preámbulo de la Segunda Guerra Mundial. Es una perspectiva que contrasta, por ejemplo, con la de uno de los avisos de Crítica, en el cual la embajada española en París en 1930, escenario del acto segundo, es visto como el espacio donde "se gestó la tragedia española", en las "vísperas del derrumbamiento de la monarquía”. Es decir, se le confiere mayor importancia y transmite una mirada más local, podríamos decir, subrayada por la construcción del receptor modelo, el "español-leal-republicano", términos que establecen una relación de sinonimia o incluso de identificación; a él le pide: "escucha la voz de la verdadera España viendo «Un hombre y su vida»"; e invita a la "familia española" a una función de "matineé" (figura 8).

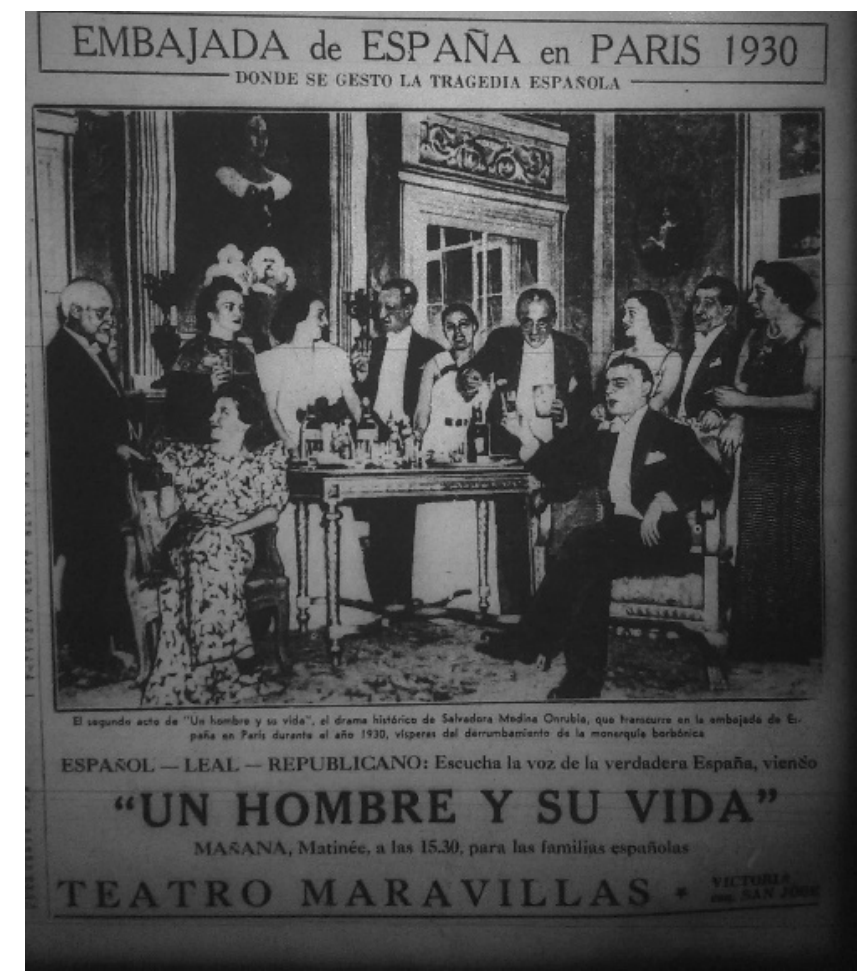

Fig. 8. Crítica, s/p.

Por último, Jaime considera el tercer acto como "la parte más desdichada del drama". "Ha fracasado, pues, otro intento - bien dirigido, honesto, sincero, esto 
no lo discutiríamos nunca- de llevar al teatro la honda tragedia de España", concluye.

En una línea editorial opuesta, pero unida por el rechazo a la obra de Medina Onrubia, Héctor Chiesa, autor de la reseña publicada en el diario católico El Pueblo (s/p.), aunque califica Un hombre y su vida como "teatro político y de ideas avanzadas" en su título, en la ficha técnica, explicita:

\begin{abstract}
Calificación moral: Mala. Aparente es el reclamo por una vida idealizada y más concorde con la humana materia. Se hace evidente apología de la idea comunista a través de las diversas épocas; material y realista es la expresión; sarcásticas las alusiones al cristianismo y al clero; confusionismo insensato matizado por momentos con alusiones capciosas. Irrealidad tendenciosa cuando se encara el problema español actual. Exposición dogmática y falaz perniciosa (destacado en el original).
\end{abstract}

Es esta una primera aproximación muy acorde a la perspectiva de la Iglesia y al lugar que ha ocupado en la Guerra Civil y, luego, en la dictadura franquista. En este mismo sentido, en su segundo párrafo, afirma que Medina Onrubia, con el "pretexto" de estrenar una obra teatral, en rigor, solo exalta perniciosamente la "gesta roja". Es interesante detenerse en la interpretación del suicidio de Iratche, al que, como es lógico, se alude de manera eufemística: este hombre, según Chiesa, termina "renunciando a la permanencia en la tierra, cuando se convence de la inutilidad de su esfuerzo y del engaño sufrido cuando creía haber logrado el medio para alcanzar la meta". Una interpretación que, sin duda, desvirtúa el gesto de Iratche y, por tanto, el mensaje de la obra.

Inmediatamente después, el autor se refiere al efecto de la obra en el público, aspecto esperable desde la perspectiva que adopta:

La historia política juega papel principal y la autora no desdeña los más intrincados procedimientos para crear el caos mental con el acopio incesante, sin ritmo, sin medida, de cuanto principio filosófico pueda aportarle ganancias inmediatas aun cuando la falsedad deliberada, la intención malevolente, sea sustancia con que elabora su discurso escénico.

Como podemos apreciar, con animosidad, le atribuye a Medina Onrubia un simple interés efectista con un objetivo comercial en el que subyace la mala intención al construir una mentira a partir de principios filosóficos de moda, que, además, se disponen de manera artísticamente fallida. $Y$ todo ello tiene un efecto absolutamente negativo en el público: "el caos mental”. Más adelante, se 
referirá a una "verborragia de luminosidad ficticia", "alusiones psicoanalíticas fuera de tiempo y respuestas prematuras mal calculadas correspondientes a sucesos actuales. Teatro de tesis, obscuro, discursivo e impersonal en resumen".

La cuestión moral, aunque desde otra perspectiva, también es abordada por el anónimo autor de la dura y muy directa reseña del 12 de marzo de El Diario Español (s/p.), profranquista:

¿Y qué decir de esos besos cinematográficos, continuos e interminables con que nos obsequian sin interrupción esa pareja de enamorados, durante un cuadro entero? [Sonia e Iratche en el primer acto]. Gracias que a la muchacha se le ocurre pegarse un tiro, que si no, a estas horas tendrían pegados todavía entre sí los labios, como estampillas al sobre. ¿A qué ese afán de tener al público con los dientes largos, sobre todo tanto tiempo?

Asimismo, resalta que "la conocida ideología política de la autora", el trascendido asunto de la obra "de palpitante actualidad española" y los "caldeados comentarios" en el "foyer del teatro" entre los "simpatizantes de los dos bandos en lucha", habían hecho suponer que allí "habría toros", pero no fue así. En una extensísima oración repleta de términos despectivos y agresivos, el autor no pierde la oportunidad para lanzar su diatriba contra el comunismo y contra la autora a quien acusa de disfrazar, con un lenguaje elocuente y con "fina literatura", su "apasionada apología" de la "ideología roja". La calidad literaria que le reconoce, sin embargo, es contradicha inmediatamente después, cuando se refiere a los discursos de los actos primero y tercero,

[...] más dignos de una barricada o de un comité comunista, que del escenario de un teatro, toda vez que para escuchar ese lenguaje y ese género de "literatura" (?), demasiados pasquines rojos se publican y se toleran en el país, amparados en que se llaman diarios y en que aquí hay libertad de prensa, aunque con sus mentiras y literatura de arrabal intoxiquen a tantos infelices, que en su ignorancia y analfabetismo son materia dispuesta para engañarlos fácilmente.

Esta invectiva contra parte de la prensa local da cuenta de que sí había "toros" en la Argentina en la arena de las ideologías y que excedía la coyuntura europea. 


\section{El Mundo (de Buenos Aires): ¿una posición equidistante?}

El Mundo intenta construir una posición neutral, pero que se resiente con el uso de algunos términos y en el desarrollo de algunas ideas.

El anónimo autor de la reseña del 11 de marzo (s/p.) le reprocha a Medina Onrubia "la disfrazada apología del comunismo" que asoma en la obra y califica de "revolución española" la sublevación contra la República, términos que recuerdan los de la reseña de La Prensa, en la que el autor, en su referencia al tercer acto, habla de "monárquicos revolucionarios" y de prisioneros arrogantes que "increpan a la monarquía, a la nobleza y al clero". El tercer acto es descripto como la "palestra" en la que se enfrentan el fascismo y el comunismo, una forma de presentación de pretendida distancia que, aunque parece no transmitir ningún tipo de valoración, lo hace, precisamente, con ese tipo de enunciación aséptica. El autor reprueba el tono declamatorio y discursivo de algunos pasajes y los convencionalismos; y concluye diciendo: "Con el triunfo aparente y «teatral» del bando comunista y el suicidio del general pone fin la autora a la comedia de la que fluye, continuadamente, a veces en medio de indudables bellezas verbales, un canto al amor y a la generosidad de los sentimientos". Los vocablos "aparente" y "teatral" (como vimos, entrecomillado en el texto original) son un indicio con doble significado: el primero, netamente referencial, ya que la suerte del bando republicano estaba echada y la Guerra Civil finalizaría tres semanas después; el segundo, de tono irónico: el triunfo del republicanismo (que aquí se identifica únicamente con el comunismo), sugerido por la liberación de los presos sin que Iratche dé ningún tipo de información a sus camaradas, no es real $y$, además, es grandilocuente, declamatorio, solo posible retóricamente. El gesto de Iratche hacia los prisioneros y su suicidio tendrían su motivación en su generosidad y en el amor por Sonia, y no en la comprensión de su doble traición, en 1906 y en 1936 (Ver la reseña de Carlos H. Faig y la de Juan Cronista). 


\section{Reflexiones finales}

A modo de cierre, sostenemos que el estreno de Un hombre y su vida, de Salvadora Medina Onrubia, se presenta como un instrumento valioso, en principio, para vislumbrar el ámbito teatral argentino de los años 30 como espacio de confluencia de artistas argentinos y españoles, importante en la red de apoyo a los republicanos, por un lado; y para ahondar en el debate sobre la Guerra Civil Española instalado en la sociedad, por otro.

Pero también nos permite conocer "la lectura de una lectura" interesante sobre la contienda que tiene como protagonista a una mujer polémica, sobresaliente en su contexto, que desafió los prejuicios y los estereotipos; una mujer que intentó intervenir sobre la realidad de manera activa y ello incluye su escritura. La publicación de la pieza y su estreno son un ejemplo de ello: desde la otra orilla, Medina Onrubia expresa su visión del mundo, cuya cifra es la contienda española, poéticamente, pero sin eufemismos y con lucidez.

La recensión y el análisis de las reseñas del estreno de Un hombre y su vida y de los avisos de promoción de la obra permiten palpar ese "espíritu de época". Pero, sobre todo, percibir que la disputa ideológica de una sociedad dividida respecto "del momento encendido de España" y también respecto de Medina Onrubia como mujer, intelectual y militante de izquierdas, tiñe la valoración de su obra y de su propia figura, aunque, no sin resistencias, ya había logrado inscribir su nombre también en la escena teatral argentina.

\section{Biblografía}

ABELLÁN, José Luis (1989). "La perspectiva del cincuentenario", Cuadernos hispanoamericanos. "El exilio español en Hispanoamérica", n. ${ }^{\circ} 473-474$, pp. 7-16, en <http://www.cervantesvirtual.com/obra/cuadernoshispanoamericanos--48/> [Fecha de consulta: 30 de marzo de 2020]

BINNS, Niall (2014). "Intelectuales de Hispanoamérica y la guerra civil española", Guaraguao, 46, pp. 9-36, en JSTOR $<$ www.jstor.org/stable/43487994> [Fecha de consulta: 1 de abril de 2020]. 
ChIESA, Héctor (1939). "En el Maravillas teatro político y de ideas avanzadas. «Un hombre y su vida» de S. Medina Onrubia”, El Pueblo, 11-03-1939, s/p.

DelGADO, Josefina (2007). "Estudio preliminar". En Salvadora Medina Onrubia, Las descentradas y otras piezas teatrales. Buenos Aires: Biblioteca Nacional-Colihue, Colección "Los raros", pp. 9-29.

DIAGO, Nel (2006). "El teatro español en Buenos Aires durante la Guerra Civil Española (1936-1939)". En Osvaldo Pelletieri (Dir.), Dos escenarios. Intercambio teatral entre España y Argentina. Buenos Aires: Galerna, pp. 75-88.

DIAGO, Nel (1995). "La Guerra Civil Española (1936-1939) en el teatro argentino de la época". En Osvaldo Pelletieri (Ed.), El teatro y los días. Estudios sobre teatro iberoamericano y argentino. Buenos Aires: Galerna, pp. 205-216.

DiAGo, Nel (1994). "Buenos Aires: la capital teatral de España (1936-1939)". En Osvaldo Pelletieri (Dir.), De Lope de Vega a Roberto Cossa. Teatro español, iberoamericano y argentino. Buenos Aires: Galerna, pp. 17-32.

"El Maravillas se reabrió con «Un hombre y su vida», de la Sra. S. Medina Onrubia", La Razón, 11-3-1939, s.a., s/p.

"El Massilia, llegado hoy, eludió dramáticamente a los submarinos", Crítica, 511-1939, s.a., p. 6.

"En el Maravillas se presentó ayer un elenco de comedia. «Un hombre y su vida» tiene factura literaria", La Nación, 11-3-1939, s.a., s/p.

FAIG, Carlos (1939). "Maravillas", Crítica, 11-3-1939, s/p.

JAIME (1939). "«Un hombre y su vida» de Salvadora M. Onrubia", 11-3-1939, $\mathrm{s} / \mathrm{p}$.

JUAN CRONISTA (1939). "Una pieza valiente y eficaz es «Un hombre y su vida», de Salvadora M. Onrubia”, Orientación, 16-3-1939, s/p.

"La emoción tensa y la unidad de ideas y propósitos son el nervio de Un hombre y su vida", El Diario, 11-3-1939, s.a., s/p.

LIDA, Clara (1991). "Del destierro a la morada". En José María NaharroCalderón (Coord.), El exilio de las Españas e 1939 en las Américas: “AAdónde fue la canción?” (pp. 63-84). Barcelona: Anthropos/Memoria Rota, pp. 63-86.

"Maravillas", El Mundo, 11-3-1939, s.a., s/p.

"Maravillas", La Prensa, 11-3-1939, s.a., s/p.

Medina OnRUBIA, Salvadora [1936] (2007). "Un hombre y su vida". En Las descentradas $y$ otras piezas teatrales. Buenos Aires: Biblioteca Nacional-Colihue, Colección "Los raros", pp. 147-247.

ORtuño MARTínEZ, Bárbara (2016). "El patriotismo desde abajo. Republicanos, inmigrantes y diplomáticos franquistas ante la idea de España en Argentina", Anuario IEHS, 2, 31, pp. 139-158, en $<$ http://anuarioiehs.unicen.edu.ar/Files/2016\%202/08\%20Anuario\%20IE HS\%2031(2)\%20d.Ortuño.pdf> [Fecha de consulta: 9 de abril de 2020].

ORtuño MARTínEZ, Bárbara (2012). “«En busca de un submarino». Crónica a bordo del buque insignia del exilio republicano en Argentina: el Massilia", Cahiers de civilisation espagnole contemporaine, n. $^{\circ} 9$, en 
<http://journals.openedition.org/ccec/4242> [Fecha de consulta: 19 de octubre de 2020].

REP (1939). "Intensa es la novedad del Maravillas. Un suceso", Última edición, 12-3-1939, s/p.

SAítTA, Sylvia (2012). "Un nuevo modelo de mujer", Teatro. La revista del Complejo Teatral de Buenos Aires (mayo), 110, pp. 30-34, en $<$ https://www.academia.edu/38201609/Un_nuevo_modelo_de_mujer_Sal vadora_Medina_Onrubia_pdf> [Fecha de consulta: 17 de octubre de 2020].

SAíTTA, Sylvia (1995). "Anarquismo, teosofía y sexualidad: Salvadora Medina Onrubia”, Mora, n. ${ }^{\circ} \quad 1$, pp. 54-59, en <https://www.academia.edu/38201587/Anarquismo_teosof\%C3\%ADa_y _sexualidad_Salvadora_Medina_Onrubia_pdf> [Fecha de consulta: 17 de octubre de 2020].

Schwarzstein, Dora (2001). Entre Franco y Perón. Memoria e identidad del exilio republicano español en Argentina. Barcelona: Crítica.

"Un debut y un estreno en el Maravillas", El Diario Español, 12-3-1939, s.a., s/p.

"Una pieza panfletaria en el Teatro Maravillas", Noticias Gráficas, 11-3-1939, s.a., s/p.

W. K. (1939). "«Un hombre y su vida». Ein spanisches Zeitdrama in drei Akten und fünf Bildern von Salvadora Medina Onrubia im Teatro Maravillas", Argentinisches Taglebatt, 24-3-1939, s/p.

ZAYAs DE LimA, Perla (1990). Diccionarios de Directores y Escenógrafos del teatro argentino. Buenos Aires: Galerna.

ZuletA, Emilia de (1999). Españoles en la Argentina. El exilio literario de 1936. Buenos Aires: Atril.

Fecha de recepción: 30 de julio de 2020.

Fecha de aceptación: 12 de noviembre de 2020. 